Acta Hispanica (2016) 21: 11-16

\title{
DISCURSO DEL DR. FERENC FISCHER
}

Querida familia doliente, estimados colegas dolientes reunidos para decir el último adiós, representantes de las misiones diplomáticas, alumnos, doctorandos, estudiantes universitarios:

El 19 de noviembre de 2016, después de padecer una grave enfermedad, con gran paciencia, falleció el catedrático Ádám Anderle a los 73 años de edad. Su muerte es una pérdida terrible para la Universidad de Szeged, la Facultad de Filosofía y Letras, el Departamento de Estudios Hispánicos y la Academia Húngara de Ciencias, así como para los profesores e investigadores hispanistas y latinoamericanistas de Hungría y del mundo entero. Hemos perdido a nuestro querido y respetado colega, amigo y maestro que, en calidad de profesor emérito, tenía varios proyectos y programas de investigación, incluso en sus últimas semanas seguía desde cerca las actividades de sus colaboradores y alumnos. A lo largo de las décadas, incluidos los últimos años, fue organizador, impulsor y conferenciante de varios congresos húngaros e internacionales. Colegas y alumnos, nos despedimos de un científico trascendental, de fama internacional y conocido incluso en ultramar, organizador de eventos científicos, un colega inolvidable y un profesor magnífico. Con la muerte de Ádám Anderle, en la historia de las investigaciones hispánicas y latinoamericanas se concluye una época marcada por su nombre.

Sus amigos, colegas y alumnos llevaban meses contemplando con preocupación su lucha heroica contra la enfermedad. Admirábamos con profundo respeto y sincero afecto que siguiera trabajando con enorme disciplina y una voluntad férrea. Trabajó hasta que se le agotaron las fuerzas, editó su libro, habló por teléfono y escribió mensajes con una increíble capacidad de trabajo, muy habitual en él, sirviendo de ejemplo excepcional en lo profesional y personal para sus colegas y también para él mismo. Nos regaló su gran conocimiento profesional, su concepto dinámico de la vida, su extraordinaria sensibilidad a los problemas y su ingeniosidad investigadora. Su gran interés por las ciencias y las experiencias que adquirió en sus numerosos viajes científicos por varias partes del mundo contribuyeron a que fuera un ejemplo a seguir para sus colegas, alumnos y doctorandos.

Contemplando su carrera, podemos afirmar que administró bien el talento que había recibido de parte del destino, incluso lo multiplicó. También ayudó a aumentar el talento de aquellos que participaron de su sabiduría, entre otros, sus dos docenas de doctorandos. Gracias a sus habilidades excepcionales y su enorme capacidad de trabajo, ascendió con rapidez por la escala jerárquica universitaria y también por la del reconocimiento internacional. Para él, el alto nivel de la investigación internacional era la exigencia fundamental, esto queda perfectamente reflejado en sus viajes de investigación y las invitaciones que recibía de las universidades extranjeras. Sabía cómo dirigir un grupo, trabajar en grupo o en solitario, como demuestran sus ensayos escritos en húngaro y español, tomos de ensayos y monografías. Rendimos homenaje también a su actividad como promotor y 
dirigente de varias asociaciones profesionales. Su trabajo extenso y eficiente fue galardonado con premios y condecoraciones húngaras y extranjeras.

Ádám Anderle tuvo que enfrentarse dos grandes desafíos personales y profesionales a lo largo de su carrera, pero logró superarlos debido a su fuerza de voluntad y su extraordinaria red de relaciones internacionales. El primer reto fue la muerte prematura del profesor Tibor Wittman en 1971, a los 49 años, cuando Ádám Anderle tenía solamente 28 años y parecía que el joven investigador se iba a quedar solo con la herencia de Wittman. Con sus propias palabras: 'Dos becas (a Cuba y al Perú) que recibí en el momento adecuado (en 1973 y en 1974/75), después de la muerte del profesor Wittman, me ayudaron a conservar el ímpetu. Mientras tanto, recibía el apoyo constante de los amigos científicos extranjeros de Wittman, junto con invitaciones a congresos, posibilidades de publicación y envíos de libros.”

Después de la muerte de Tibor Wittman, la red de relaciones profesionales internacionales estabilizó el futuro profesional de Ádám Anderle. Más tarde, agradeció esta confianza generosamente a los grandes maestros hispanistas-latinoamericanistas de la Europa Occidental de entonces, los amigos y contemporáneos del profesor Wittman, la generación que fundó la Asociación de Historiadores Latinoamericanistas Europeos (AHILA), organización que entonces vivió su periodo de auge. Fue un gran reconocimiento y una muestra de confianza anticipada, y también un nuevo desafío, que en 1984 se le concediera a Szeged (Hungría) y personalmente al joven Ádám Anderle la oportunidad de organizar el VIII Congreso de AHILA. Podemos afirmar que el congreso de AHILA de 1987, organizado en Szeged, fue uno de los mejores. Estaba muy orgulloso de ello y también de que en 1987 fuera elegido presidente de AHILA, mientras que todavía existía la división del mundo entre este y oeste. Tenía entonces 44 años, este periodo fue seguramente una de las etapas más importantes de su carrera.

Otro periodo difícil de Ádám Anderle llegó a finales de los años 80 y a comienzos de los años 90. Volvemos a citarle: "Asumí varios conflictos por aquel entonces. Y tenía varios motivos para tener miedo. Por eso, como presidente (de AHILA - F.F.), pedí la ayuda de nuestra asociación europea: ... después de una beca española de tres meses, trabajé como profesor visitante en Gotinga. Estuve allí cuando se llevó a cabo el cambio de sistema. Después de este cambio, tras un breve intento, dejé el mundo de la política. A partir del Grupo de Investigación (de Historia de América Latina - F. F.), organicé el Departamento de Estudios Hispánicos en 1993 y participé en la creación del nuevo sistema de la formación de doctorado de la universidad."

Pienso que cuando el Departamento de Estudios Hispánicos, fundado por él, celebró el $10^{\circ}$ aniversario en septiembre de 2003, pudo estar orgulloso. Sabía que después del Grupo de Investigación de Historia de América Latina, fundado en 1982, estableció una unidad científica que a lo largo de los diez años transcurridos logró integrarse en el sistema de la enseñanza superior húngara y en la red de relaciones internacionales. Los antiguos miembros o colaboradores del Grupo de Investigación incrementaron en varias ciudades húngaras (Veszprém, Kaposvár, Pécs, Budapest) el 


\section{Dr. Ferenc Fischer}

círculo de profesores universitarios que se dedicaban al mundo iberoamericano. Los investigadores provenientes del alma mater de Szeged crearon nuevos centros docentes y de investigación; como efecto común de todo esto, se multiplicó el número de alumnos que estudiaban español como lengua extranjera en los institutos de enseñanza bilingüe. El gobierno español reconoció este proceso favorable cuando decidió establecer un Instituto Cervantes en Budapest, inaugurado en septiembre de 2004 por el entonces Príncipe de Asturias Felipe y su esposa. Con la integración de Hungría en la Unión Europea se ofrecieron nuevas posibilidades para ampliar las relaciones con los dos países de la península ibérica. En 2005, durante la visita oficial del presidente de la República de Hungría, Ferenc Mádl a Madrid, a petición del presidente, Ádám Anderle también formó parte de la delegación húngara. El rey Juan Carlos le otorgó la Orden de Isabel la Católica en reconocimiento de su actividad científica destacada. En este periodo escribió su libro Hungría y España. Relaciones milenarias, publicado en 2006 en húngaro y en 2007 en español.

En el tomo que se publicó para el 65 cumpleaños de Ádám Anderle - Az identitás régi és új koordinátái (Las antiguas y nuevas coordenadas de la identidad) -, tanto los representantes húngaros y extranjeros de la disciplina como los investigadores húngaros del mundo extra ibérico rindieron homenaje al profesor Anderle con sus ensayos. Esto, junto con la extensa lista de nombres de la Tabula Gratulatoria, refleja fielmente la amplia red de relaciones científicas de Ádám Anderle.

Si tomamos en cuenta toda la obra de Ádám Anderle, podemos afirmar que era un historiador universal que abarcaba una dimensión espacio-temporal muy amplia. Sus investigaciones le dirigían, en la dimensión cronológica, desde la Alta Edad Media hasta la actualidad y, en el espacio global, desde el Perú, a través de Cuba y España, hasta la historia húngara, esta última integrada en los procesos históricos universales. Recuerdo nuestras conversaciones en las que el profesor siempre volvía a la misma idea: los historiadores húngaros (y los de Europa Centro-Oriental), al investigar temas históricos universales o relacionados con el mundo ibérico o latinoamericano tienen una gran ventaja: el pasado tormentoso de Hungría y de la región, la experiencia del atraso y el estado semiperiférico nos brindan una sensibilidad peculiar. Ádám Anderle representaba esta convicción: si el historiador húngaro logra identificar las fuentes adecuadas en los archivos extranjeros, entonces -por bien o por mal, acostumbrados a las circunstancias de Europa Central- al investigar el pasado de los países y sociedades de las periferias y semiperiferias, nosotros, historiadores universales húngaros, no estamos restringidos por las trabas históricas del pasado colonial impuesto por la metrópoli imperial o las ambiciones y posiciones de las potencias mundiales. Toda la obra de Ádám Anderle apuntaba hacia esta dirección y una de sus herencias intelectuales más importantes a conservar es que logró disolver el exagerado eurocentrismo de la conciencia histórica húngara. Su objetivo era lograr que la dimensión amplia europea y mundial fuera mucho más que un eslogan de moda, que ambicionáramos investigar las relaciones globales y, a la vez, latinoamericanas de los procesos húngaros y europeos. 
En el espíritu de este punto de vista de la historia universal, muy sensible a los problemas planteados, contó con muchos discípulos; varias docenas de alumnos, autores de trabajos del círculo científico estudiantil, de memorias de fin del grado y de tesis doctorales fueron dirigidos por el profesor Anderle mediante conversaciones profesionales, mantenidas con el fin de plantear cuestiones de investigación y designar objetivos. Además, determinó el interés científico de muchos de estos alumnos por años o décadas y les animó a participar en becas para viajar al extranjero, ejerciendo influencia sobre las principales direcciones de su carrera profesional.

Era un excelente pedagogo y organizador, apoyaba a un gran número de estudiantes, facilitándoles la posibilidad de viajar al extranjero, publicar y seguir con sus estudios. Por esta razón, podemos afirmar que era un maestro y pedagogo investigador también en el terreno de la gestión del talento. Esto formaba parte importante de su obra no solo en Szeged, sino también a nivel nacional: fue uno de los dirigentes de la Sección de Humanidades del Consejo del Círculo Científico de Estudiantes (OTDT), presidente (1996-2002), presidente honorífico y desde 2002 miembro de la presidencia gerente del OTDT. Ádám Anderle escribió el prólogo del grueso libro de resúmenes publicado con ocasión de la organización de la Sección de Humanidades del 30 Congreso del Círculo Científico de Estudiantes en abril de 2011; en este prólogo, resumió las tres décadas de este movimiento estudiantil, demostrando también el credo de este maestro: "El movimiento científico estudiantil de Hungría, que se desenvolvió en nuestro país desde el año escolar de 1950-51, es único. Según tenemos entendido, no existe tal movimiento universitario en ningún otro país. Este movimiento, que sirve los objetivos de la autodidáctica, la formación de élites y científicos, es el fruto de la cooperación de los individuos científicos sugestivos, maestros carismáticos y jóvenes estudiantes que estaban buscando nuevos caminos. La fuerza impulsora de la atmósfera honesta y estimulante que se ha formado alrededor de los profesores y científicos destacados y el descubrimiento de los resultados propios, complacen a los jóvenes investigadores, dentro del marco de las relaciones abiertas, democráticas e interactivas plasmadas con sus maestros." La actividad de este maestro carismático, con la cual ayudaba a la formación de talentos científicos, fue reconocida con el título profesor maestro y con la medalla de oro Honoris Causa Pro Scientia.

Creo que tuve una excelente relación de profesor-alumno, y posteriormente de colega con Ádám Anderle. Pertenezco a la primera promoción (1974-1977) de la formación especial de Historia de América Latina, especialización que posteriormente eligieron muchos alumnos junto a la formación de profesores de dos carreras. Colaboré con Ádám Anderle hasta 1987 en el Grupo de Investigación de Historia de América Latina, fundado por él mismo en 1982, y trabajamos juntos en 1987 en la organización del VIII Congreso de AHILA de Szeged. Durante estos años fui testigo de su enorme capacidad de trabajo, y cuando nos encontrábamos por las mañanas, él, como solía levantarse temprano, ya había escrito algunos mensajes, fragmentos de ensayos o había leído artículos. Nunca olvidaré aquellas conversaciones fascinantes que mantenía con él 


\section{Dr. Ferenc Fischer}

hasta 1987, durante mis años en Szeged, luego en Pécs y, más tarde, en aquellos congresos internacionales (en Liverpool, Sevilla, Cádiz o Madrid, entre otros), donde el grupo más considerable lo formaba la delegación de los hispanistas húngaros e investigadores latinoamericanistas del antiguo bloque del este, todos ex-alumnos suyos.

Estos encuentros y conversaciones personales y de atmósfera amistosa representaban para mí y para nosotros excepcionales valores personales y profesionales, es un enorme dolor que no podamos continuarlos. Este año hablamos por teléfono varias veces sobre su enfermedad y yo admiraba su enorme fuerza de voluntad, lucha y confianza. Antes de su tercer tratamiento clínico, le envié un mensaje con una canción descargada desde YouTube, El Cóndor Pasa, interpretada por Plácido Domingo. Contestó con ilusión: “es una canción muy querida para mí, la escuché por primera vez con la peruana Ima Sumac. Es una buena señal."

Estimadas personas aquí congregadas:

En la persona de Ádám Anderle, llevamos luto por el catedrático respetado, el distinguido especialista de su área científica, el ilustre dirigente universitario y el profesor reconocido y firme de alumnos y doctorandos. Es un antiguo deseo de los intelectuales que su nombre se perpetúe en sus obras, porque tal vez sea la única manera de alcanzar la inmortalidad. El profesor Ádám Anderle era un verdadero maestro cuya presencia perdurará a través de sus alumnos antiguos y nuevos. Ahora que ya no está con nosotros, es tarea de sus colegas y alumnos que conservemos y cuidemos su herencia.

La muerte impide que la obra científica de nuestro respetado y querido Colega y Maestro, construida durante varias décadas, siga ampliándose. Pero esta magnífica obra creada por Ádám Anderle, el científico de renombre internacional, no se desvanecerá: su influencia e impacto seguramente subsistirán, en primer lugar, en sus colegas húngaros y extranjeros, sus discípulos, organizaciones e instituciones establecidas por él, sus obras, y la atmósfera académica que le rodeaba hasta el último momento. Se mantendrá, ante todo, en aquellos investigadores mayores y jóvenes que siguen sus huellas a lo largo de sus indagaciones y resultados, y que siguen construyendo esta magnífica obra. No existe mayor honor para la posteridad que participar en el proseguimiento de la obra de un excelente científico y un hombre honrado. La Familia puede recobrar aliento y fuerza sabiendo que la obra y los logros científicos de importancia internacional de su querido familiar pervivirán.

Querido Ádám:

Nos despedimos de ti en nombre de los profesores, doctorandos y alumnos. Agradecemos al destino que hayamos podido conocerte y que hayamos podido ser tus discípulos, colaboradores y amigos. Echaremos de menos tus conferencias en las aulas de Szeged y en los congresos húngaros e internacionales. No volveremos a escuchar tus razonamientos, pero nuestro corazón y memoria lo guardarán todo. Has cumplido tu misión en tu entorno profesional y personal más reducido y también en el más amplio: 
tus colegas y alumnos agradecidos aprecian tu obra, te respetan y te admiran; por eso se acordarán de ti. Para todos nosotros, los que estamos aquí en esta última despedida, es un gran dolor que ya no podemos decirte cuánto te respetábamos y queríamos, qué bueno era tenerte entre nosotros. Estamos muy tristes, te echaremos mucho de menos, te debemos mucho.

En nombre de los colegas europeos y de ultramar de Ádám Anderle, transmito su mensaje: "Descanse en paz." El profesor Jussi Pakkasvirta, el presidente del Consejo Europeo de Investigación Social de América Latina (CEISAL), escribió desde Helsinki lo siguiente: "Que triste noticia nos toca hoy. Expreso mi gran pésame por la muerte de un gran colega, personalmente y como el presidente de CEISAL. Como un estudiante de maestría en los 1980, ya estuve usando el libro de Adam "Los movimientos políticos en Perú", aprendiendo mucho. Honrando la memoria de Adam Anderle". El profesor Stefan Rinke, presidente de AHILA, envió su pésame desde Berlín: "En nombre de AHILA les mando mi más sentido pésame a los colegas húngaros. Hemos perdido con el Prof. Dr. Ádám Anderle a un gran amigo de nuestra asociación y un excelente historiador."

Acompañamos a Enikő en el duelo y compartimos el dolor de tu familia y parientes.

¿Que te acompañe la bendición de nuestro afecto, amistad y aprecio en tu camino hacia la eternidad! 